\title{
Facilitating participation: a health action zone experience
}

Susan M Carr, Charlotte L Clarke, Jeanie Molyneux and Diane Jones Community Health and Education Studies Research Centre, Northumbria University, UK

\begin{abstract}
Partnership working, engagement and participation of service recipients and providers are issues at the core of UK and international health and social care policies. Although always considered desirable, recent legislation makes this practice a legal imperative in England. However, the operationalization of the concepts pose a number of challenges. This paper draws on evaluative data to examine how these concepts were addressed within one of the largest health action zones (HAZ) in England. The research took a generative perspective and was intended to promote learning, deepen understanding, model actions and consequences, and to provide a guide to decision making. Three approaches of theories of change, pluralistic evaluation and soft systems methodology were combined in the research design. Data was collected through 39 individual tape-recorded interviews with people involved with HAZ at both strategic and operational levels. The findings allowed partnership and engagement activity to be categorized into two domains, those that led to entrenchment in old practices and those that facilitated engaging with a partnership and community involvement ethos. By making the facilitating and inhibiting variables more explicit, the potential for working to a partnership philosophy is enhanced.
\end{abstract}

Key words: community involvement; health action zones; partnership

Received: July 2005; accepted: January 2006

\section{Introduction}

Partnership working, engagement and participation of service recipients and providers are issues at the core of UK government and international health policy (Department of Health, 2001; Morgan, 2001). This is not a totally new agenda, with the Alma Ata Declaration of 1978 being a key driver to the increasing focus on these issues. Despite this history, participation in health has 'perpetual allure, persistent challenge' (Morgan, 2001: 221). Current policy (Department of Health, 2000; 2001; 2002a; $2002 \mathrm{~b}$ ) is driving to extend joint working and extend the range of partners involved. Despite this policy

Address for correspondence: Dr Susan M Carr, Reader in Public Health and Primary Care, Community Health and Education Studies Research Centre, Northumbria University, Coach Lane (East), Benton, Newcastle upon Tyne, NE7 7XA, UK. Email: sue.carr@northumbria.ac.uk prominence, the concepts and their operationalization continue to require further clarity and development. As summarized by Matka et al. (2002: 97).

Government initiatives, from the development of primary care trusts (PCTs) and health improvement and modernization plans (HIMPs) through to neighbourhood renewal and local strategic partnerships (LSPs) all stress partnership and community involvement as a fundamental to achieving change, but what does this mean in practice. [our italics]

This paper examines how concepts of community participation and partnership working were addressed within one of the largest and arguably most structurally complex health action zones (HAZ) in England. HAZs were set up in the late 1990s to harness a range of partnership working in order to tackle poor health. They were designed to give opportunities to develop new ways of working 
which would cut across geographical and structural barriers known to be detrimental to achieving successful outcomes. HAZ should therefore, in theory, provide a context in which partnership and engagement can flourish.

Partnership and models of engagement are the focus of three of the seven principles on which HAZs were based (Anon, 2000):

- Engaging communities: 'involving the public in planning services and empowering service users and patients to take responsibility for their own health and decisions on care.'

- Engaging front-line staff: 'involving staff in developing and implementing strategy, developing flexible and responsive organizations and encouraging and supporting innovation in service delivery.'

- Partnership and multi-agency working: 'recognizing that people receive services from a range of different agencies and that these services need to be co-ordinated to achieve the maximum benefit.'

This paper draws on data from an evaluation of Tyne and Wear HAZ to consider achievements and processes in relation to these three principles. These experiences are related to the subject literature base and messages are identified that are relevant to progressing any activity that seeks to achieve partnership and engagement.

\section{Literature}

A review of a range of literature identified three key issues:

1) What are some of the known problems with partnership working and engagement?

2) How can partnership working and engagement be facilitated?

3) How can repetition of ineffective practice be avoided and successful practice be progressed?

A number of tensions are identified in the literature relating to differences between organizations, costs and risks of joint working and developing trust, the pace of change and the impact of organization restructuring. Similar issues are present in the five barriers to partnership working listed by Holtom (2001: 431): structural, procedural, financial, professional, status and legitimacy. He concludes that the crucial ingredients to effective partnership working are:

Partnerships need to be built on firm foundations of mutual understanding across local stakeholders, and effective partnership working ultimately depends more on cultural change and leadership than on joint structures and joint systems. (p. 444)

One of the key inhibitors relates to the equal distribution of power within partnerships. Problems arise when there is an imbalance. In relation to health care priorities and delivery, Milewa et al. (2002) identify an enduring dominance of health service managers and clinicians over patients and local communities. Other complexities could also be drawn from this statement in relation to the diversity of power within the clinician groupings. Added to this is the problem identified by Hudson (2002) of the neglect of interprofessional relationship development in favour of a stronger focus on interorganizational issues. In their discussion of the national HAZ evaluation, Matka et al. (2002) identify power imbalances as a particular issue in relation to the voluntary and community sectors.

Partnership working cannot be seen as a quick outcome; it is a process that takes time aided by transformational rather than the more traditional control and command leadership. Indeed, there needs to be a continuum of outcome achievement, with the necessity of some 'quick wins' both to prove to others that the strategy has credibility and to give positive feedback to those working to address the challenges of new ways of working. A degree of nurturing must occur, especially in relation to those participants who may have limited experience of participating in such activities such as voluntary agencies and community groups.

Patient and public participation in service planning and delivery is a challenging agenda that has been operationalized in a variety of ways. Multiple interpretations and understandings of the terms involvement and participation by different agencies are a source of contention. Criticisms of reductionism have been made of approaches that only involve selected subgroups of the public or patient groups and which limit involvement to only parts of the planning and delivery processes. Cook (2002: 516) describes consultation as: 'a crucial, yet deeply problematic issue' dogged with criticisms of tokenism and unrepresentativeness. Matka et al. (2002) identify 
that a frequent, though largely ineffective, solution to consultation is to invite a small number of organization representatives to participate in a planning process. Patient and public involvement is then often limited to problem identification and not progressed to solution development.

Cook (2002) suggests that confusion as to the purpose of consultation is a core component of the interpreting and operationalizing problems. Specifically, whether consultation is for consumerist or empowerment purposes. Consequently, consultation and patient participation may be viewed as an event rather than a productive process, with confusion over when it has been successfully achieved.

One challenge for HAZs was to facilitate more productive approaches and in keeping with general government policy to 'modernize' consultation and community involvement. Some of the structural barriers had been addressed and there was explicit policy intent to engage in partnership and community engagement. However, HAZ was also open to what Charlesworth (2001) refers to as a policy paradox; the policy drive for partnership set within a context of rapid policy change and demand for outcomes measures. The potential consequence of this context is for: 'an element of retreat to core business and it is still too early for organizations to see partnership working itself as core business' (p. 285). Cook (2002) highlights a further paradox in the collision of community empowerment and the drive for evidence based policy and practice calling into question to what degree the community can determine need and service development.

There appears to be only a limited amount of cumulative or shared learning in relation to many previous directives to encourage partnership working. Of concern, in research exploring interorganization partnerships in primary care and health improvement programmes, Charlesworth (2001: 284) highlights:

What is noticeable about these preliminary research findings is that the same problems and mistakes continue to be encountered in partnership working, albeit involving different organizations and contexts.

In a similar vein, this paper gives further examples of what appear to be well publicized and entrenched hurdles to partnership and participation practices. However, adhering to the learning philosophy of HAZ, the paper also discusses the drivers and inhibitors identified in this HAZ evaluation project which may assist in moving from an entrenchment perspective to one in which engagement may be achieved. In this way the paper contributes to the operationalization of what has now become a service imperative.

\section{Methodology}

Tyne and Wear HAZ was one of the more complex zones, spanning five localities: Gateshead, Newcastle, North Tyneside, South Tyneside, and Sunderland. Structurally, Tyne and Wear HAZ was made up of five local health partnerships (LHPs) from these localities. The evaluation of Tyne and Wear HAZ took place during 2000-2002 and used qualitative methodology to synthesize diverse experiences. The evaluation took a generative rather than an outcome driven approach. The intention therefore was to promote learning, identify choices, deepen understanding and to provide a guide to decision making. The overall aim was to analyse the process of implementation and impacts of Tyne and Wear HAZ.

This paper is based on one aspect of a larger evaluation project that is reported in full elsewhere (Clarke et al., 2002). Three theoretical approaches informed the design of the evaluation:

- Theories of change, which is defined by Connell et al. (1995) as 'a systematic and cumulative study of the links between activities, outcomes and contexts of the initiative.'

- Pluralistic evaluation (Smith and Cantley, 1985), which assumes that different stakeholders may have different ideas about the 'success' of developments.

- Soft systems methodology (Checkland and Scholes, 1990), which aims to understand the political and social systems underpinning organizational change and to describe the management and accountability systems.

The research approach aimed to be productive and useful for participants in that it may assist them in reflection and in 'making sense' of their HAZ experience. Multiple funded projects, in particular, experience considerable evaluation and performance management demands, so it was important that the research did not place undue demands on participants' time. 
Table 1 Words included on interview key word sheet

\begin{tabular}{llll}
\hline Sense of direction & Leadership & Empowerment & Enabling \\
Policy & Strategy & Opportunities & Creativity \\
Integration & Capacity for change & Boundaries & Partnership \\
Barriers & Access & Sharing & Diversity \\
Collaboration & People & Competition & Flexibility \\
Agendas & Ownership & Knowledge & Diversity \\
Regeneration & Sense of direction & Whole system & Evidence \\
\hline
\end{tabular}

This aspect of the evaluation maps out the variability in the theories of change or the assumptions driving practice held by a variety of people in a variety of contexts. The sampling method used was that of "purposive stratified maximum variation' (Patton, 1990) designed to facilitate the maximum generation of information, rather than seeking generalization. Using set inclusion criteria (HAZ themes, positive and negative HAZ experiences, HAZ principles, locality and agency) the five HAZ co-ordinators and the performance manager identified a sample of 108 people involved in HAZ. From this larger sample, 39 people were interviewed by two members of the research team (DJ \& JM). This allowed for a breadth of perspectives across the HAZ. This included people able to comment on both strategic and operational issues. Data was collected through tape-recorded individual interviews. The interview format aimed to facilitate analysis of the process of engaging with HAZ activity during the interview and to restrict descriptive and historic accounts of HAZ activity. This was achieved by a key word sheet drawn from the principles of HAZ and processes identified in the literature as influencing organizational change. The words used are presented in Table 1. All tapes were transcribed and the data entered into the data management software package NUD*IST. Briefly the analysis process involved identifying open codes that described themes in the data. These codes were then grouped to create categories. Exploration of conceptual models of issues was a concurrent activity, used to generate questions to ask of the data.

\section{Findings}

This section details how partnership working and community engagement were practiced in this HAZ. Many of the barriers and facilitators to partnership working and community engagement

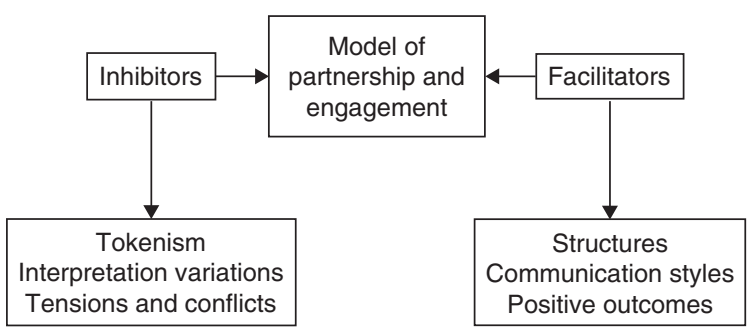

Figure 1 Inhibitors and facilitators in partnership and engagement

already highlighted in the literature were reiterated. However, the findings were intended to say more than that well-reported issues were manifest in this evaluation. It was possible to catagorize partnership working and community engagement into two: those that led to entrenchment in old practices and those that facilitated engagement with the partnership and community involvement ethos. There were very positive examples of partnership and it is possible to identify the styles of practice and the organization structures that engender this outcome. Despite there being a strong commitment within the ethos of HAZ to partnership working and among many participants in the HAZ process people did experience both tensions and barriers in trying to work in an engagement rather than an entrenchment model.

Inhibiting and facilitating factors in the development of partnerships and engagement are summarized in Figure 1. The issues are explored, drawing on respondent quotes for illustration, and this data is then related to the literature on this subject area.

\section{Inhibitors}

Three factors: of taking a tokenistic approach, misinterpreting the concepts of partnership working and engagement and tensions between participants were highlighted as being key inhibitors. 
There was a diversity of experience of partnership working and engagement. For some individuals and agencies this was a significant challenge and something of a new experience. Those with a history of attempting to work in this way started with high expectations of the possibilities of progressing, with these practices being facilitated by HAZ. However, many later voiced frustration that progress was not happening or not happening with sufficient speed. It must be acknowledged though that their enthusiasm may have engendered a degree of inappropriate expectation of what HAZ could achieve in the timescale and contexts.

\section{Tokenism}

There was a level of inconsistency as to when true engagement or partnership was achieved as opposed to when a tokenistic approach was adopted. The respondents quoted below observed that many approaches are not regarded as genuine attempts to seek engagement but are tokenistic. As a consequence, feelings of disillusionment and cynicism could result:

I think we're still doing things to communities. We may be in certain circumstances doing things with communities, but I don't think in any circumstance that I know that we are doing things for communities. If we are, we are doing them in a reactive rather than proactive way. (p. 24)

I represent an area which is one of the worst socially deprived areas in the country, if you look at the health figures. The people there have had survey upon survey but they don't see any results. (p. 11)

Tokenism was not necessarily a purposeful choice, but an indicator of a lack of appreciation of the complexity of partnership and engagement working. Some agencies appeared to consider that they were working in partnership mode, when by their description, they were only engaging in consultation.

Another example of tokenism related to some agencies accepting engagement with a small proportion of a community as achieving the community involvement aim. Communities were acknowledged to have multiple interests and needs and not to be a single cohesive entity. The views and priorities of different groups within the same area may be quite different and may have aspects that are in conflict with each other. Engaging communities may therefore be seen as creating opportunities for the engagement of those who wish to be involved. The task of contacting and engaging the most marginalized, excluded or isolated people or groups within any community is challenging, more so than working exclusively with those who are the easiest to contact and who put themselves forward. This leads to the debate of the representativeness of views put forward by the 'community':

I really want to know what the people think about the services and not just three or four people, or half a dozen people who've got themselves motivated, are activated to sort of represent people. I have a funny sort of feeling about this representation idea, that people are being encouraged to think of themselves as representatives. Because I don't think ... I think everybody is a representative of their own experience and not a representative of a community. (p. 25)

Concerns of tokenism at a policy level were also raised. Engagement and partnership were acknowledged to require considerable time investment Achievement of these activities could not be expected to be an immediate outcome. Although they are core to the HAZ philosophy, questions were raised about compatibility with the pressure on HAZ to demonstrate change and results in a short timescale:

I don't know if we've got the luxury of time to develop a community or a set of small communities. So I'm not against it, I like community development work but I don't know ... It is a slow process and I don't know if it's too slow for what we need. (p. 25)

\section{Tensions and conflicts}

There were HAZ projects working with people in localities with the aim of engaging the communities in each of the five districts in Tyne and Wear and these had a wide variety of particular themes and/or geographical focuses. While some of these were geared primarily to providing direct opportunities that engaged with people's own priorities and needs and to building 'social capital', there was also an element in many of them of enabling and 
supporting people to participate in formal and informal processes around health and social care service planning. The degree to which the influencing of the service planning element of the initiatives could succeed is of course, to a large extent, dependent on the receptivity of the statutory organizations and of the joint planning mechanisms. This was regarded as very variable and while there were references to more openness and responsiveness, there were also many observations made about the barriers and obstacles that both deter involvement and fail to respond to issues, ideas and suggestions raised by people in the community.

Conflict between community views and employers of community development workers was another issue. A classic community work tension was referred to by some of those working in a community development setting. As people gain in confidence they may make demands which give rise to conflict with the employers of the worker. For example:

They've got a big capacity and they're using it, you know they're utilizing people, they're utilizing the skills of people and you know a lot of the time there's real conflict, because they're coming into conflict with the people who employ me. (p. 34)

There were also examples of professionals' priorities differing from those of the community. Several respondents observed that the priorities which people in many communities have in terms of what affects their health are often very different to the priorities as perceived by professionals and they are not necessarily about health services. This was observed to cause tension in forums where 'health' is being interpreted in narrow terms:

In a couple of the groups what local people were saying ... was completely different to what the workers were saying, for example, somebody talking about the need for their fences to be repaired. It's old hat for housing officers because you repair them and somebody nicks them, and you replace them and somebody takes them to burn them on the fire. But for these people living in that area that's a really important thing about feeling secure. (p. 7)
Perceptions of power imbalances were a particular tension for smaller organizations and especially the voluntary sector.

I get so frustrated by this because the voluntary sector people like us, we work for peanuts but we're as professional as any of those people who sit behind office desks in the local authority or in the HAZ office. But you feel as if you're treated as if you know, you're not skilled. (p. 19)

\section{Interpretation variations}

Vocabulary and terminology was identified as a barrier to engagement and a source of dissonance and misinterpretations between parties. This referred not only to professional client communications but also related to interagency communication. Two people, both in senior positions, referred to the use of acronyms in particular as a barrier to involvement:

I do feel that when you talk to the NHS, everything is acronyms. I find it the most incredible organization for acronyms. They don't speak in English and as a consequence of that they don't speak to people. (p. 16)

Another problem was identified as some professionals assuming that partnership and engagement activities could be made to fit into the current structures and organizations. This suggested a rather superficial or simplistic interpretation of the process and practice of partnership and engagement. Respondents identified meetings conducted in a traditional and exclusive manner and style, one saying that although:

partnership boards were about widening community participation, decision making processes, more accountability, more openness, local democracy issues ... and that's why that whole structure was set up [they often seemed] quite oppressive or closed shops again where certain people controlled the agenda, controlled the decision making. (p.15)

There were accounts of efforts made by projects to support local people to get involved in committees, but that the meetings could be intimidating and confusing and little effort was generally made to enable people to get involved. An instance was mentioned of a community member being expected to take 
messages back to the community rather than being listened to at the meeting:

Agendas and chairmen and things like that, they're totally meaningless to the vast majority of people. We treat it as sort of second nature, as normal behaviour, but it isn't. (p. 16)

One voluntary sector member of a local health partnership said that:

There are actually only two voluntary sector reps left on the health partnership board, out of six, because nobody else can get their head round where it fits into their job. (p. 3)

She added that she had been prepared to put work in outside of work time to facilitate these kinds of processes, and went on to say that if HAZ finished tomorrow:

I wouldn't miss the structural bit and I would have enough contacts now, personally, to continue my own partnership working without the mechanism that I have tried to fit into, because I really feel as a person I have tried to fit into mechanisms that haven't worked for me. (p. 3)

Although there had been successes in achieving the engagement of front-line staff, this was generally felt to be lacking strategic or systematic intent. There was also a sense that it was not entirely clear what engagement of staff might mean and what would be needed to put it into effect. The interpretation of the principle was therefore often vague and lacking clarity.

\section{Facilitators}

Three factors were highlighted as facilitating partnership and community involvement: having the right structures to allow this type of practice, developing the appropriate communication styles and achieving positive outcomes.

Participation and engagement do not just happen, they have to be facilitated. Examples were given of reconfiguring processes and structures to allow for this as opposed to trying to achieve it within current organization frameworks. A crucial determinant was recognizing that there are multiple voices and that what have traditionally been quiet voices need to be given the opportunity to be heard.

\section{Structures}

In one area there was HAZ funding for a threeyear appointment to a whole systems facilitator post, using this as a method to consult with and develop local communities:

It means inviting participants from communities that maybe haven't had a voice in the past, to come together as equals with service providers to actually express their needs and views on services. People come together from the whole system as equals, they listen to each other, and they speak. Everyone has a right to be heard and listened to and everybody's point of view is respected. (p. 1)

Opportunities to become influential and exercise that influence had to be created. Some projects had promoted opportunities for engagement in health and social care planning, and this was feeding into involvement in the new PCT and in community planning and neighbourhood renewal. Some of this work was felt to be starting to generate a real dialogue and have an influence in:

getting across to the health sector that community views need to be listened to. (p. 20)

\section{Communication approaches - asking the right question in the right way}

Successful engagement activities recognized that the communication approach was crucial and that not everyone has the capacity to engage everyone else, that is, a selection and matching process must be undertaken. For example, one project enlisted local people as community development workers:

Basically, I go in, suit, tie, I may as well be a Martian, but if some of my staff go in there now, they're in the style. You know they've got the tattoo, the earrings you know, they're very good, they're intelligent bright people who can actually talk to the people, try and contact them in their own language, pick up those issues in the system. (p. 16)

This understanding that it is not only about dressing and speaking in a similar way to the population, but actually recognizing their perceptions and interpretations was evident in an initiative which aimed to get away from identifying the priorities purely 
in terms of National Health Service services, or lifestyle changes, and to ask:

what do people who live and work here know about what's really causing people health problems and how housing makes a difference. (p. 7)

The professionals had not previously considered many of the ideas that emerged from such processes.

\section{Positive outcomes}

There were many examples of positive outcomes and participants needed to know that their efforts were bearing fruit in order to continue to exert energy and effort in meeting the challenges of working in new ways. At one level there were examples of concrete achievements:

There are lots of examples ... where health professionals have got together with service providers from the voluntary sector, from local authority and individual carers and lay people who work out in the community, who've come together to say 'we can work together to improve services' sometimes for an individual but sometimes for a whole group of people. (p. 1)

At another level positive outcomes can be seen as an appreciation that HAZ could only achieve so much, that partnership working and engagement practices would not be achieved overnight, but that progress had been made and understandings of what was involved had been developed. As one respondent noted:

One of the things that I think HAZ has done is to really make us aware of the boundaries and begin to work across them much more than I think we did before. (p. 6)

\section{Discussion}

It is appropriate at this point to revisit the three broad issues identified in the literature review section of this paper. There is a substantial literature on the known problems with partnership working and engagement. Factors that create barriers and factors that facilitate involvement are also well reported. The philosophy and design of HAZ contributed to tackling some of the acknowledged barriers to partnership and engagement, specifically around structural, financial and procedural issues. However, although the context was set for facilitation, many of these well-reported problems were manifest in this HAZ evaluation.

There is now a considerable policy history of partnership working and community engagement, although until recently it had a rather peripheral status. Different agencies have therefore developed different levels of understanding and practice on these issues. Health services in particular were highlighted as being an agency that showed signs of struggling with these practices. The acknowledged problems of diversity of remit and competing priorities must make a significant contribution to this scenario. Historical practices take time to change and new ways of working take time to develop. Structural developments in relation to HAZ experience may have contributed to this general thrust towards heightened levels of participation.

An issue, which everyone had to negotiate, was 'what exactly does partnership working and community engagement mean for me'. Confusions and reductionist practices reported in the literature were also evident here (Cook, 2002; Matka et al., 2002).

Developing partnerships and engagement are complex activities, which perhaps have not received appropriate levels of analysis and debate before implementation has been attempted. This manifest in agencies working to different definitions and interpretations of partnership and engagement. The evaluation demonstrated that the role and remit of both professional and lay participants' demands considered definition and nurturing. There is still some outstanding work to fully answer Matka et al.'s (2002) question of what engagement and participation mean in practice.

Good examples of partnership working and community engagement were met in this evaluation. That is a very important comment to make. Despite the well-reported problems, progress is being made towards achieving these modes of practice. However, this draws us to revisit the third key issue highlighted in the literature review, the avoidance of ineffective practice and progression of successful practice. The HAZ design has tackled some of the structural issues. The importance of leadership and cultural changes can now be seen to be as significant in the achievement of successful partnership working and community engagement. There appear 
Table 2 Engagement and entrenchment decision making framework

\begin{tabular}{lll}
\hline Patterns of entrenchment & Key questions & Patterns of engagement \\
\hline Projectitis - development defined & What forms of project management & Activity seen as evolution and \\
as time limited project & promote engagement? & emergent aspects sought \\
Developing community capacity & What accountability structures are & The expertise of all stakeholders is \\
compromised by conventional & required in developing community & recognized and administrative \\
administrative systems & capacity? & systems accommodating \\
Consultation processes have & How can a dialogue be created and & Communities and front line staff are \\
negligible impact on & sustained between commissioners, & primary drivers for activities and work \\
decision making & providers and service users? & in partnership with service providers \\
Interagency working and & How can fledgling partnerships be & Interagency and community \\
community involvement & protected to allow their development? & involvement integral to development
\end{tabular}

vulnerable to policy, organizational

and person changes

to be some approaches that inhibit the achievement of partnership and engagement and others that facilitate it. In other words, some approaches and models entrench service providers in a model, which inhibits partnership and community engagement. Other models of activity facilitate engagement with partnership working.

Where patterns of entrenchment were present power holders and organizations were closed to cultural shifts, held on to power and control, were resistant to opportunities for innovation, and took a superficial approach to partnership and community engagement. There are big players and small players and limited confidence in the contribution of the latter by the former. On the other hand, examples of patterns of engagement displayed trust and respect across the multiple stakeholders. Expertise and knowledge bases were seen to be diverse and not exclusive to certain participants. Real dialogue is attempted which means that mutual understandings develop, there is sustained communication and change is negotiated and dynamic.

A key question posed to the researchers by the commissioners of the research were how can we best proceed with the HAZ intent and what lessons can we share with colleagues developing other initiatives such as strategic health authorities. As a consequence of this evaluation it was possible to provide the commissioners with a framework that could be used to explore choices in developing services to increase the potential for partnership and engagement potential. It may not always be possible to make the 'partnership' choice, but the making of an informed choice is the critical issue. In
Table 2 a number of questions frequently met in decision making are answered providing an engagement and an entrenchment option. The examples provided specifically address the power distribution, leadership, integrated partnership processes and developmental time issues identified in the literature review. These are useful tools to guide service development and to facilitate ongoing evaluation of achievement of partnership and engagement models of practice. This may also facilitate progressive analysis of what these terms actually mean, thereby developing understanding.

\section{Conclusions}

This HAZ experience has reiterated some of the problems with partnership and community involvement reported in the literature. It reinforces that crucial determinants are respect for multiple perspectives, equal distribution of power, clarity of practice model, and open communication styles and systems. The findings of this evaluation therefore go some way to help move the partnership and engagement philosophy a stage further by making the variables for entrenchment and engagement more explicit. By reconfiguring the challenges into models or approaches to practice organization and delivery, the necessary cultural shifts and leadership requirements can be highlighted and facilitated. The entrenchment and engagement decision making framework allows consideration of partnership and community involvement to be integral to service decision making processes. 


\section{Susan M Carr et al.}

\section{References}

Anon. 2000: HAZ it worked. Nursing Standard 14,13-17.

Charlesworth, J. 2001: Negotiating and managing partnership in primary care. Health and Social Care in the Community 9 , 279-85.

Checkland, P. and Scholes, J. 1990: Soft systems methodology in action. Chichester: Wiley.

Clarke, C., Procter, S., Carr, S.M., Jones, D. and Molyneux, J. 2002: Tyne and Wear health action zone evaluation: patterns of engagement and entrenchment. University of Northumbria, unpublished report.

Connell, J.P. 1995: New approaches to evaluating community initiatives: concepts, methods and contexts. Colorado: The Aspen Institute.

Cook, D. 2002: Consultation, for a change? Engaging users and communities in the policy process. Social Policy \& Administration 36, 516-31.

Department of Health. 2000: The NHS plan: a plan for investment. A plan for reform. London: Department of Health.

Department of Health. 2001: Health and social care act. London: Department of Health.

Department of Health. 2002a: Shifting the balance of power within the NHS - securing delivery. London: Department of Health.
Department of Health. 2002b: Partnership working. National service frameworks: a practical aid to implementation in primary care. London: Department of Health.

Holtom, M. 2001: The partnership imperative. Joint working between social services and health. Journal of Management in Medicine 15, 430-45.

Hudson, B. 2002: Interprofessionality in health and social care: the Achilles' heel of partnership. Journal of Interprofessional Care 16, 7-17.

Matka, E., Barnes, M. and Sullivan, H. 2002: Health action zones: creating alliances to achieve change. Policy Studies 23, 97-106.

Milewa, T., Dowswell, G. and Harrison, S. 2002: Partnerships, power and the 'new' politics of community participation in British health care. Social Policy \& Administration 36, December, 796-809.

Morgan, L.M. 2001: Community participation in health: perpetual allure, persistent challenge. Health Policy \& Planning 16, 221-30.

Patton, M.Q. 1990: Qualitative evaluation and research methods, second edition. Newbury Park, CA: Sage Publications.

Smith, G. and Cantley, C. 1985: Assessing health care: a study in organisational evaluation. Buckingham: Open University Press.

World Health Organization. 1978: Declaration of Alma Ata. Geneva: World Health Organization. 